\title{
The impact of obesity-related single nucleotide polymorphisms on satiety
}

\author{
A. Dougkas ${ }^{1,3}$, A. M. Minihane ${ }^{2}$, D. I. Givens ${ }^{3}$, C. K. Reynolds ${ }^{3}$ and P. Yaqoob ${ }^{1}$ \\ ${ }^{1}$ Hugh Sinclair Human Nutrition Group, School of Chemistry, Food Biosciences and Pharmacy, Faculty of Life Sciences \\ University of Reading, Reading RG6 6AP, UK, ${ }^{2}$ Department of Nutrition, Norwich Medical School, University of East \\ Anglia (UEA), Norwich NR4 7TJ, UK and ${ }^{3}$ School of Agriculture, Policy and Development, Faculty of Life Sciences, \\ University of Reading, Reading RG6 6AR, UK
}

\begin{abstract}
Although behavioural factors are major determinants of obesity risk, genetic variation is also known to significantly impact on body weight regulation $^{(1)}$. A number of studies reported a heritable component for the regulation of appetite and eating behaviour, although the individual polymorphisms and their 'size effect' are not fully elucidated ${ }^{(2)}$. The aim of the present study was to examine the relationships between appetite ratings and specific SNP in overweight men.

In a randomised crossover trial, forty overweight men [age: 32 (SD 9) years; BMI $\left(\mathrm{kg} / \mathrm{m}^{2}\right.$ ): 27 (SD 2)] attended four sessions one week apart and received three isoenergetic and isovolumetric servings of dairy snacks or water (control). Appetite ratings were determined using visual analogue scales (VAS) and energy intake at the ad libitum lunch was assessed 90 min after the snacks. Individuals were genotyped for SNP in the fat mass and obesity-associated $(F T O)$, leptin $(L E P)$, leptin receptor $(L E P R)$ and variant near melanocortin-4 receptor $(M C 4 R)$ genes.
\end{abstract}

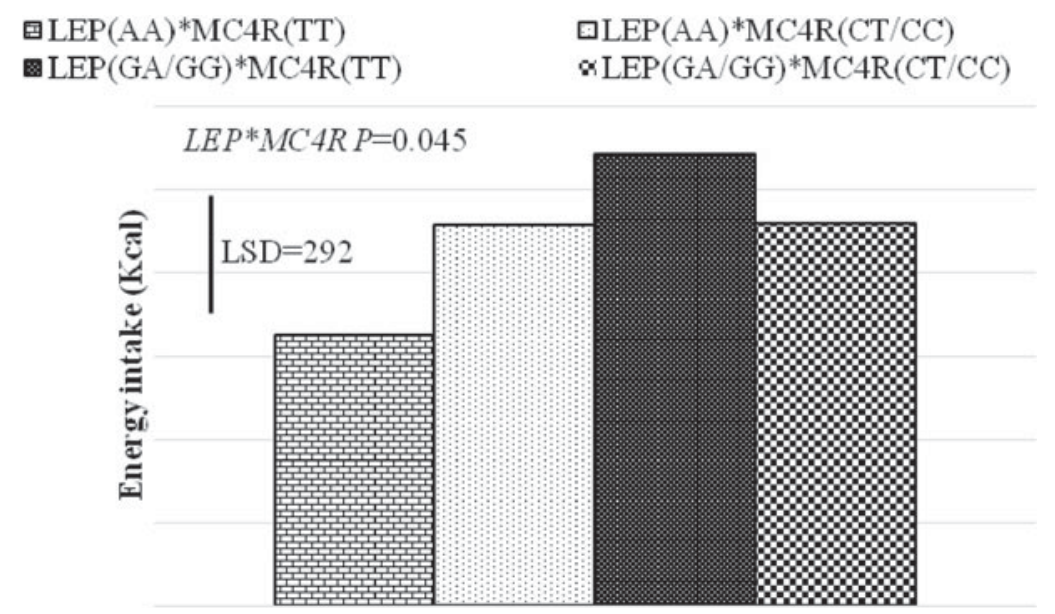

Fig. 1. $L E P * M C 4 R$ interaction.

Postprandial response in fullness was $18.2 \%(P=0.026)$ lower in TA/AA (dominant) carriers compared with TT carriers in rs9939609 (FTO) and $17.0 \%(P=0.020)$ lower in GA/GG (dominant) carriers compared with the AA carriers in rs 7799039 (LEP). When interactions among the four genes were examined, a significant interaction for energy intake involving rs7799039 (LEP) and rs17782313 (MC4R) was observed. Under a dominant inheritance model, individuals with the lower energy intake were over represented among AA and TT carriers in rs7799039 $(L E P)$ and rs17782313 $(M C 4 R)$, respectively, compared with GA/GG and TT carriers in these SNP, respectively $(P=0.011)$, with the rs7799039 (LEP) having the main effect $(P=0.041)$ (Fig. 1).

In conclusion, the FTO and $L E P$ polymorphisms are related to feeling of fullness and may play a role in the regulation of food intake. Further studies are required to confirm the observations and investigate the 'penetrance' of these genotypes in additional population subgroups.

1. Walley AJ, Asher JE \& Froguel P (2009) Nat Rev Genet 10, 431-442.

2. Grimm ER \& Steinle NI (2011) Nutr Rev 69(1), 52-60. 